\title{
Pudendal neuralgia
}

INSERM

\section{Source}

INSERM. (1999). Orphanet: an online rare disease and orphan drug data base. $\underline{\text { Pudendal }}$ neuralgia. ORPHA:60039

Pudendal neuralgia (PN) is a chronic neuropathic pain, aggravated by sitting and for which no organic cause can be found by imaging studies. It is often associated with pelvic dysfunction. 